\title{
Self-care for anxiety and depression: a comparison of evidence from Cochrane reviews and practice to inform decision- making and priority-setting
}

\author{
Karen Pilkington ${ }^{1 *}$ (10 and Lisa Susan Wieland ${ }^{2}$
}

\begin{abstract}
Background: Self-care refers to a range of activities and approaches undertaken by an individual to maintain health and manage ill-health which may include various complementary or alternative approaches. The purpose of this study was to identify the self-care approaches used by the general public for depression and anxiety, assess the usefulness of Cochrane reviews for informing decisions on self-care and highlight any gaps in the evidence.

Methods: Searches were carried out for surveys of self-care for anxiety and/or depression and for Cochrane reviews and protocols of interventions with potential for use in self-care. Data was extracted from each review and Plain Language Summaries assessed for content, consistency and readability. Interventions reported in surveys and in Cochrane reviews were compared and effectiveness of each assessed.

Results: Surveys from 10 countries reported a variety of self-care interventions, 17 of which appeared in 2 or more surveys and which included dietary supplements, herbal medicines, mind-body therapies and various forms of exercise. Twenty-two reviews and 5 protocols on potential self-care interventions were identified, the majority in depression. Twelve interventions were judged effective or promising, most with small effect sizes. Readability of summaries was highly variable: half were written at college/university level. Several commonly used approaches were not covered by Cochrane reviews.

Conclusions: This study has revealed the interventions currently used by the general public which are judged effective or promising based on Cochrane reviews. Some disparity is highlighted between interventions used in practice and the availability of reliable evidence, and in the presentation of effectiveness and safety. Being able to direct patients to reliable, accessible information is a positive step in ensuring effective patient-centered, evidenceinformed care. Addressing gaps, ensuring consistency and increasing usability of evidence intended for the general public will support this goal.
\end{abstract}

Keywords: Anxiety disorders, Depression, Depressive disorder, Evidence-based practice, Self-care, Systematic reviews

\footnotetext{
* Correspondence: karen.pilkington@port.ac.uk

'School of Health and Care Professions, University of Portsmouth, James Watson West, 2 King Richard 1st Road, Portsmouth P01 2FR, UK

Full list of author information is available at the end of the article
}

C C The Author(s). 2020 Open Access This article is licensed under a Creative Commons Attribution 4.0 International License, which permits use, sharing, adaptation, distribution and reproduction in any medium or format, as long as you give appropriate credit to the original author(s) and the source, provide a link to the Creative Commons licence, and indicate if changes were made. The images or other third party material in this article are included in the article's Creative Commons licence, unless indicated otherwise in a credit line to the material. If material is not included in the article's Creative Commons licence and your intended use is not permitted by statutory regulation or exceeds the permitted use, you will need to obtain permission directly from the copyright holder. To view a copy of this licence, visit http://creativecommons.org/licenses/by/4.0/ The Creative Commons Public Domain Dedication waiver (http://creativecommons.org/publicdomain/zero/1.0/) applies to the data made available in this article, unless otherwise stated in a credit line to the data. 


\section{Background}

The World Health Organization (WHO) defines selfcare as "the ability of individuals, families and communities to promote health, prevent disease, maintain health, and to cope with illness and disability with or without the support of a health-care provider" [1]. The WHO has proposed a global perspective on self-care in traditional medicine which encompasses a range of approaches and activities. These include health promotion and illness prevention, healthy lifestyle including diet and physical activities, techniques that may promote health such as acupressure and massage, exercises for health including qigong, tai chi and yoga, and meditation for mental and spiritual wellbeing, in addition to herbal and other traditional remedies for disease management [1]. Based on this definition, it is clear that there is potential for a range of complementary approaches to contribute to self-care.

There is, however, some variation in how the term self-care is understood and applied in practice with several terms used to describe the role that individuals may take in assessing and managing their own health. 'Selfmanagement' is considered to relate particularly to longterm health conditions and is often implemented as an ongoing partnership between the patient and his/her health-care providers [2]. In contrast, some organisations use the term 'self-care' to refer solely to the efforts a healthy individual takes to maintain health and prevent illness [2] while others perceive self-diagnosis/testing to fall within the scope of self-care [3]. A review of selfcare in mental health suggests that it is a 'broad, inclusive concept, not distinct from but encompassing those related concepts of recovery, self-management and selfhelp' [4]. Nevertheless, according to the WHO definition, appropriate self-medication and self-treatment are key components of self-care [1].

Many countries are placing increasing emphasis on the decision-making and actions taken by individuals to manage their own health. In the UK, health policy has continued to focus on self-management/self-care in the context of promoting personal responsibility for health [5]. In Japan, self-help is seen as a potential, albeit partial, solution to the financial burden of an aging population which is placing increasing demands on central funding of healthcare [6]. Self-care is also being increasingly adopted in China with decision-making influenced by self-perceived illness status, economic circumstances, and education [7]. Web-based research has demonstrated significant yet comparable levels of self-care (40$55 \%$ of respondents) in Australia, Japan, UK and US suggesting that the trend is not influenced by the health care provision model [8].

Self-care takes on particular importance in the field of mental health due to issues related to access to treatment. Individuals with mental health conditions are often reluctant to seek medical advice [9-11] despite considerable efforts to address the perceived stigma around conditions such as depression and anxiety [12]. Those experiencing these problems may be unwilling to take or adhere to pharmacological treatments [13] or unable to access relevant psychological therapies [14, 15]. Indeed, lack of treatment for anxiety disorders and depression has been shown to be a global issue [14].

For those seeking to manage their own anxiety or depression, whether through choice or circumstance, a whole array of treatments or activities are on offer. Within the field of mental health, some authors have distinguished between informal approaches: 'simple things an individual can do on their own without the need for professional guidance' and guided self-help involving professional supervision [16]. Those recovering from depression may have to 'navigate' a range of pharmacological and psychological therapies as well as support groups [17], and health services are not perceived to offer help in guiding self-treatment and selecting approaches from the huge number of options that are available [18]. Whether self-care is facilitated and overseen by a health professional, or is self-motivated and self-monitored, there is a requirement for reliable information on effectiveness and safety. It is particularly important for individuals to have access to comprehensive and understandable information when the strategies are self-chosen in order to make informed decisions and, before using a self-care health intervention, to ensure that it does no harm to the individual $[19,20]$.

Cochrane reviews are widely recognized as the most reliable form of evidence on specific health interventions. Topics covered by Cochrane reviews are largely those proposed by the review teams working in that particular area. The target audience for Cochrane reviews is broad: as the website states 'Cochrane is for anyone who is interested in using high-quality information to make health decisions. Whether you are a doctor or nurse, patient or carer, researcher or funder ...', (https://www. cochrane.org/about-us) Thus, it is conceivable, and indeed intended, that patients (and /or members of the general public) may seek to base their decision-making around the conclusions of Cochrane reviews. To support this, each review has a 'plain language summary' on the first page. However, it is not clear to what extent Cochrane reviews address potential self-care approaches and whether the format would support and inform selfcare by those with conditions such as anxiety and depression.

The aim of this study was to identify the approaches used most commonly in self-care of anxiety and depression through collating results of surveys of use, to assess evidence from Cochrane reviews on potential self-care 
interventions for depression and anxiety and the usefulness of the reviews for informing self-care of depression and anxiety, and to ascertain potential 'gaps' in Cochrane evidence for commonly used or recommended self-care approaches to treat or prevent these conditions.

\section{Materials and methods}

A novel approach was taken that was developed specifically for this study and which has the potential to be applied in other areas and contexts. The most commonly used or recommended self-care strategies for depression or anxiety are likely to vary in different countries and health care systems. As Cochrane is a global organisation providing evidence across national boundaries, we aimed to identify the most commonly used or recommended strategies across countries. To achieve this, we produced a 'snapshot' by collating results from published international, national or regional surveys on the topic. We then identified Cochrane reviews on potential selfcare interventions for depression or anxiety. We assessed the review characteristics and conclusions, and how the conclusions were presented to the public, before comparing the topic coverage between the surveys and the Cochrane reviews and presenting the findings of the Cochrane reviews.

\section{Searching and selection of surveys describing self-care for depression and/or anxiety}

To identify self-care approaches commonly used or recommended for depression or anxiety, we searched PubMed, MEDLINE, EMBASE, AMED and PsycINFO for surveys reporting use of self-care interventions using the search strategies reported in Appendix 1. Initial searches for surveys were carried out in April 2017; these were updated in February 2019 and updated and extended in April 2020. Surveys were selected that reported use or endorsement of specific self-care approaches on a regional, national or international basis specifically for anxiety and/or depression. Surveys were excluded that: only reported use by category e.g. nonconventional/complementary versus conventional approaches; were conducted within a single organization (e.g. one clinic or health centre) only; where use was in anxious/ depressed populations but not specifically for anxiety or depression. Conference abstracts and dissertations were also excluded. Each set of search results was screened by one author (KP) to select possibly relevant surveys. Full-texts of these were obtained and any surveys where relevance was unclear were screened by both authors with any disagreements on inclusion resolved by discussion.

\section{Selection of self-care interventions for depression and/or anxiety}

To generate a list of self-care interventions known to be used frequently in practice, we extracted all self-care approaches to the treatment or prevention of depression and anxiety that were mentioned in any survey, focusing on those that were endorsed by at least $5 \%$ of survey respondents. We also sought evidence of expert recommendations on effective self-help therapies for depression or anxiety. We considered self-care approaches that were endorsed in two or more surveys of consumers or in one consumer study plus one expert study, to be those most commonly used or recommended for depression or anxiety. We compared the list of these approaches to the interventions covered in relevant Cochrane reviews. The selection process is summarised in Fig. 1.

\section{Searching and selection of Cochrane reviews on self-care for depression and/or anxiety}

We screened all published reviews from the Cochrane Common Mental Disorders Review Group (CCMD) or grouped under the topic of 'depression' or 'anxiety' on the Cochrane Library webpage (cochranelibrary.com/ cdsr/reviews/topics) to identify reviews on potential selfcare interventions for preventing or treating depression or anxiety. Initial searching was conducted in April 2017, and repeated in March 2018, February 2019, and March 2020 for new or updated records. We defined self-care interventions as interventions that could be selected and applied without the assistance of a practitioner or professional. We included interventions that could involve practitioner guidance, but did not necessarily do so (e.g., vitamins, yoga), and included only selfcare interventions for risk factors, symptoms or medical diagnoses of depression or anxiety in adults (age 18 and older). We excluded the following reviews: those of interventions for trauma-related conditions (e.g., posttraumatic stress disorder), obsessive-compulsive disorder, panic disorder, bipolar disorder, or any other conditions not specifically described as depression or anxiety; those of interventions that relied upon either conventional or alternative practitioners (e.g., prescription medicine, talk therapy, acupuncture); reviews focused on children and young people, even if some trials may have included people aged over 18 years; reviews that had been withdrawn from publication. Protocols that clearly covered self-care were included as an indication of research in progress and limited data was extracted from these. Protocols were excluded if it was unclear whether the final review would include self-care interventions.

Both authors independently screened the title and abstract of each review, and each review selected by one or both authors as possibly relevant was then independently screened in full by both authors. Disagreements surrounding inclusion were resolved by discussion. 


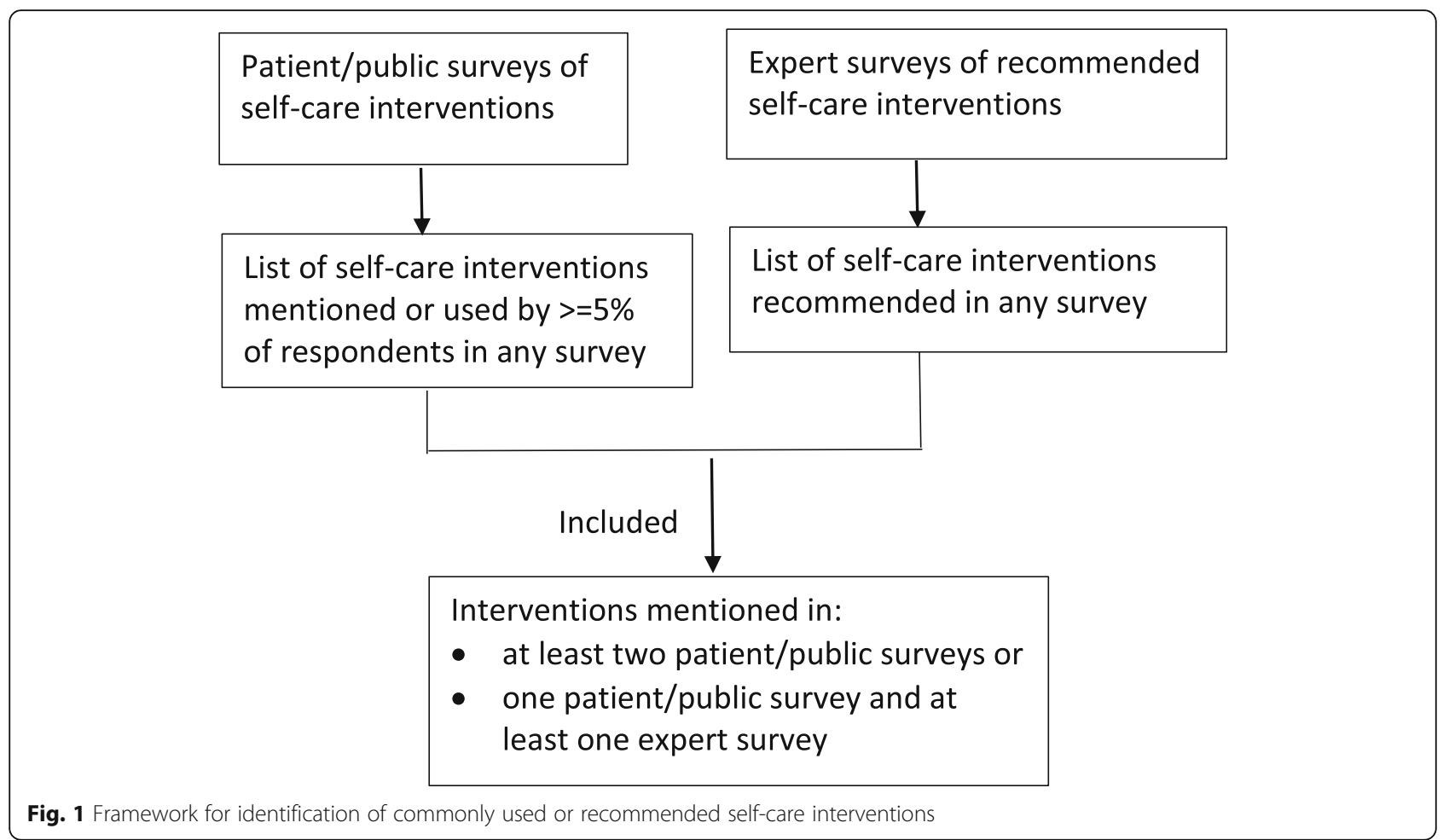

Information extracted from Cochrane reviews on self-care for depression and/or anxiety

We extracted descriptive data from included reviews into an Excel spreadsheet. Information included the country of the corresponding author, sources of external funding, date of the latest review update, the condition (depression or anxiety), the approach (treatment or prevention), the population, the type of self-care intervention, the main comparisons, whether any meta-analyses were done, and the review conclusions. We independently categorized the interventions as effective (where the review concluded there was evidence of a beneficial effect), promising (where there was some evidence but this was limited e.g. one or two trials, or low quality, and not conclusive) or unclear (where the evidence did not provide a clear indication of effectiveness or otherwise) based on the conclusions. We then compared decisions and agreed a final category for each intervention. We also assessed the readability of the plain language summary of each review with the Flesch Reading Ease test, which generates a readability score based upon the word and sentence length [21]. Higher scores on the Flesch Reading Ease test indicate text that is easier to read. Scores of 60 or above indicate plain English that is readable by the average adult, scores of 30 to 60 indicate text that is readable by advanced or college students, and scores below 30 indicate that text is readable by college/ university graduates [22].
Comparison of data from surveys with Cochrane reviews We compared the list of interventions compiled from collation of the surveys with the interventions assessed within the Cochrane reviews and presented this comparison in tabular form.

\section{Results}

Surveys on self-care for depression and/or anxiety

The initial searches for surveys of self-care retrieved a total of 2396 records of which 182 were duplicates; additional and extended searches in April 2020 retrieved an additional 1609 records so that the total screened was 3823 . The screening process is summarized in Fig. 2. Twenty surveys of patient or public recommendations or use of self-care interventions for depression and/or anxiety were included, 5 from Australia [23-27], 1 from Austria [28], 2 from Germany [29, 30], 2 from Italy [31, 32], 1 from Korea [33], 1 from the Netherlands [34], 1 from Portugal [35], 2 from Taiwan [36, 37], and 5 from the USA [38-42]. The surveys were online, postal, telephone, or face-to-face surveys of consumers or the general public, in which opinions were solicited on selfhelp strategies to manage symptoms of depression $(n=15)$, or both depression and anxiety $(n=5)$. We also found three surveys involving recommendations for self-help strategies from experts [43-45].

One expert survey [44] from Australia used a Delphi method to solicit recommendations for effective selfcare strategies for sub-threshold depression from 


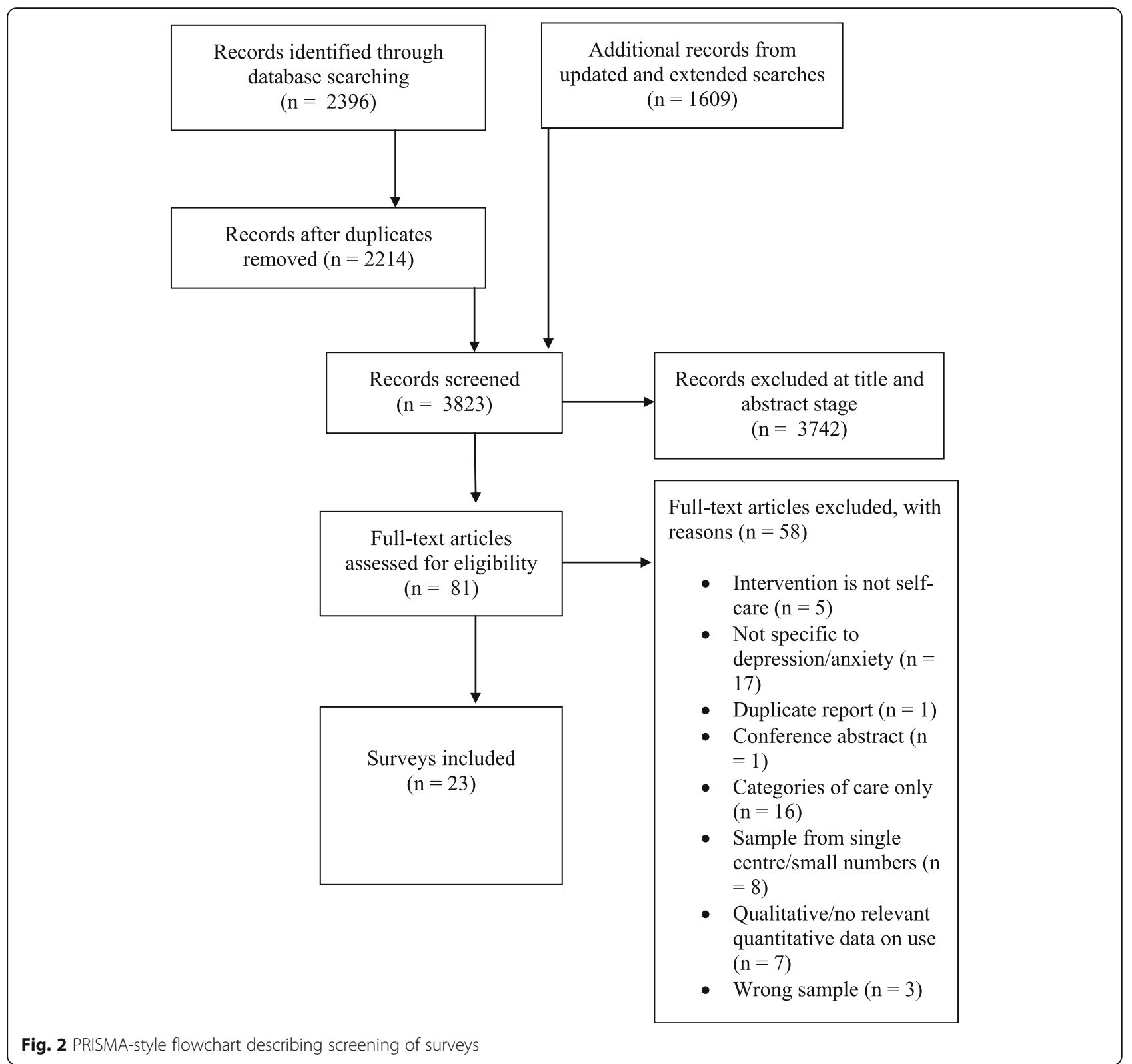

international panels of depression consumers and clinicians. An additional survey by the same research team used similar methods to identify recommendations for effective self-care strategies for anxiety [43]. We extracted a list of 10 interventions from the strategies that were listed in these studies as endorsed by at least $80 \%$ of both consumers and clinicians (a cut-off point used by the authors when assessing consensus): bibliotherapy, dietary change, exercise, internet self-help, meditation, mindfulness, pets/ animals, relaxation, self-help groups, and exposure to sunlight. We also found a third survey carried out among Norwegian psychologists, in which bibliotherapy and internet self-help were both commonly recommended for patients with depression or anxiety [45]. See Table 1 for a summary of both the patient or public surveys and the expert surveys included for this overview.

We selected 17 strategies mentioned by at least $5 \%$ of respondents in at least two of the 20 patient or public surveys: aromatherapy, bibliotherapy, dietary improvement, exercise, fish oil/omega-3, herbal medicine (most frequently St. John's wort (Hypericum perforatum)), homeopathy, internet selfhelp, massage, meditation/mindfulness, music, pets, prayer/ spirituality, relaxation, self-help groups, vitamins/minerals, and yoga. We selected an additional two strategies recommended in one of the three expert surveys and by at least $5 \%$ of respondents in one of the 20 patient or public surveys: natural environments and sunlight exposure. We therefore identified a total of 19 strategies that we considered to be 
Table 1 Surveys collecting information on use and recommendations for self-care interventions in depression or anxiety

\begin{tabular}{|c|c|c|c|}
\hline Author year & Country & $\begin{array}{l}\text { Sample } \\
\text { size }\end{array}$ & Sample and methods \\
\hline \multicolumn{4}{|c|}{ Surveys describing self-care interventions used for depression or anxiety $(n=20)$} \\
\hline Jorm 2004 [23] & Australia & $N=6618$ & $\begin{array}{l}\text { Postal survey of community sample of adults in Canberra and south-east New South Wales, collecting in- } \\
\text { formation on actions taken to cope with depression during the past } 6 \text { months. }\end{array}$ \\
\hline Olesen 2010 [27] & Australia & $N=8841$ & $\begin{array}{l}\text { Nationally representative face-to-face survey of Australian adults, collecting information on self- } \\
\text { management strategies for a diagnosed affective or anxiety disorder during the past } 12 \text { months. }\end{array}$ \\
\hline Parker 2007 [24] & Australia & $N=2692$ & $\begin{array}{l}\text { Online survey of Australian adults who has experienced depression, investigating perceived effectiveness } \\
\text { of self-help and other strategies. }\end{array}$ \\
\hline Parslow 2004 [26] & Australia & $N=7485$ & $\begin{array}{l}\text { Postal survey of community sample of adults in the Canberra environs, collecting information on use of } \\
\text { CAM to treat symptoms of depression or anxiety. }\end{array}$ \\
\hline $\begin{array}{l}\text { Proudfoot } 2015 \\
\text { [25] }\end{array}$ & Australia & $N=465$ & $\begin{array}{l}\text { National online survey of Australian men investigating positive strategies to prevent and manage } \\
\text { depression }\end{array}$ \\
\hline $\begin{array}{l}\text { Holzinger } 2012 \\
{[28]}\end{array}$ & Austria & $N=1205$ & $\begin{array}{l}\text { Telephone survey of Viennese adults assessing help-seeking } \\
\text { to a vignette depicting a case of moderate depression. }\end{array}$ \\
\hline Lowe 2006 [29] & Germany & $N=87$ & $\begin{array}{l}\text { Face-to-face interview of outpatients with depression, investigating attitudes and preferences for self- } \\
\text { management to improve mental well-being. }\end{array}$ \\
\hline $\begin{array}{l}\text { Riedel-Heller } \\
2005 \text { [30] }\end{array}$ & Germany & $N=2516$ & $\begin{array}{l}\text { Nationally representative face-to-face interview of adults collecting information on preferred treatment } \\
\text { options in response to a vignette representing major depressive disorder }\end{array}$ \\
\hline Carta 2014 [31] & Italy & $N=1200$ & $\begin{array}{l}\text { Telephone survey of Sardinian adults assessing help-seeking and treatment recommendations in re- } \\
\text { sponse to a vignette depicting a case of depression. }\end{array}$ \\
\hline $\begin{array}{l}\text { Munizza } 2013 \\
{[32]}\end{array}$ & Italy & $N=1001$ & $\begin{array}{l}\text { Telephone survey of Italian adults assessing beliefs and attitudes regarding depression etiology and } \\
\text { treatment. }\end{array}$ \\
\hline Shin 2014 [33] & Korea & $N=1214$ & $\begin{array}{l}\text { Online survey of national sample of adults from the community, patients with sub-threshold or mild de- } \\
\text { pression, and psychiatrists about the use and helpfulness of self-help for depression. }\end{array}$ \\
\hline $\begin{array}{l}\text { Loureiro } 2013 \\
\text { [35] }\end{array}$ & Portugal & $N=4938$ & $\begin{array}{l}\text { Supervised written survey of Portuguese young people presented with a vignette depicting depression } \\
\text { and asked questions concerning self-help strategies. }\end{array}$ \\
\hline Hsu 2009 [36] & Taiwan & $N=201$ & $\begin{array}{l}\text { Telephone survey of Taiwanese adults recently discharged from psychiatric hospitalization, collecting } \\
\text { information on CAM use for depression. }\end{array}$ \\
\hline Tsai 2006 [37] & Taiwan & $N=220$ & $\begin{array}{l}\text { Face-to-face interviews of elderly nursing home residents, investigating self-care strategies to manage de- } \\
\text { pressive symptoms. }\end{array}$ \\
\hline $\begin{array}{l}\text { Van Grieken } 2018 \\
{[34,46]}\end{array}$ & $\begin{array}{l}\text { The } \\
\text { Netherlands }\end{array}$ & $N=193$ & $\begin{array}{l}\text { Online survey assessing use and perceived helpfulness of self-management strategies in participants re- } \\
\text { cently recovered from an episode of major depression. }\end{array}$ \\
\hline $\begin{array}{l}\text { Bazargan } 2008 \\
\text { [39] }\end{array}$ & USA & $N=315$ & $\begin{array}{l}\text { Face-to-face interview regarding frequency and type of CAM use for depression among sample of } \\
\text { primarily African American and Hispanic individuals at clinics in Los Angeles, California screening positive } \\
\text { for mild to severe depression. }\end{array}$ \\
\hline $\begin{array}{l}\text { Bystritsky } 2012 \\
{[40]}\end{array}$ & USA & $N=1004$ & $\begin{array}{l}\text { Telephone survey of CAM therapies to help with 'mood or energy' among primary care patients } \\
\text { diagnosed with an anxiety disorder and participating in a randomized trial (CALM). }\end{array}$ \\
\hline $\begin{array}{l}\text { Grzywacz } 2002 \\
{[42]}\end{array}$ & USA & $N=5827$ & $\begin{array}{l}\text { In-person survey of a national sample of older adults (age } 65+\text { ) collecting inform } \\
\text { treat mental health. }\end{array}$ \\
\hline Kessler 2001 [38] & USA & $N=266$ & $\begin{array}{l}\text { Telephone survey of nationally representative sample of adults on CAM therapies used for treatment of } \\
\text { self-defined 'anxiety attacks' or 'severe depression' during the previous } 12 \text { months. }\end{array}$ \\
\hline Musil 2017 [41] & USA & $N=335$ & $\begin{array}{l}\text { Mailed survey assessing self-management of depression symptoms among Ohio grandmothers with self- } \\
\text { identified depression. }\end{array}$ \\
\hline \multicolumn{4}{|c|}{ Surveys recommending self-care interventions for depression or anxiety $(n=3)$} \\
\hline Morgan 2009 [44] & Australia & $N=97$ & $\begin{array}{l}\text { Delphi survey of international panel of experts and consumers on recommended interventions for sub- } \\
\text { threshold depression }\end{array}$ \\
\hline Morgan 2016 [43] & Australia & $N=83$ & $\begin{array}{l}\text { Delphi survey of international panel of experts and consumers on recommended interventions for sub- } \\
\text { threshold anxiety }\end{array}$ \\
\hline $\begin{array}{l}\text { Nordgreen } 2011 \\
{[45]}\end{array}$ & Norway & $N=815$ & $\begin{array}{l}\text { Online survey of Norwegian psychologists, collecting information on self-help strategies recommended } \\
\text { to patients with anxiety or depression. }\end{array}$ \\
\hline
\end{tabular}


commonly used or recommended. See Table 2 for a listing of each of the self-help therapies from patient/public surveys or expert surveys.

\section{Cochrane reviews on self-care for depression and/or anxiety}

We identified 62 records from the Cochrane Library browse by topic list of reviews on Mental Health/Anxiety Disorders and 116 records from the Cochrane Library browse by topic list of reviews on Mental Health/ Depression. We identified 228 records from the Cochrane Library browse by Review Group list of CCMD reviews. Finally, we checked the internal Cochrane database (Archie) for further review documents belonging to CCMD and identified 320 review documents with $C D$ numbers indicating publication in the Cochrane Library. These CD numbers retrieved 239 records from the Cochrane Library. After repeating searches in 2018, 2019 and 2020, we retrieved a total of 609 records of which 292 were duplicates. We screened a total of 317 records and included a total of 22 reviews [47-67] and five protocols [68-72] (see Fig. 3).
The included protocols and reviews were published between 2004 and 2019. Twenty focused on depression including seasonal affective disorder [47, 49-51, 54, 55, $57,58,60-62,64-72], 6$ focused on anxiety $[48,52,53$, 59, 63, 73], 1 covered both depression and anxiety [56]. Four of the reviews and three of the protocols focused on prevention of depression or anxiety, one of the reviews focused on both prevention and treatment of depression, and the remaining 17 reviews and two protocols focused on treatment of depression or anxiety. Interventions were primarily herbal or dietary supplements. Twelve therapies were judged effective or promising, most with small effect sizes. Those judged effective were exercise, relaxation and St John's wort for depression. Tryptophan and 5-hydroxytryptophan for depression and kava extract for anxiety were judged effective but associated with serious adverse effects precluding use. 'Promising' interventions included bibliotherapy, internet-based self-help, meditation/mindfulness for anxiety and specific dietary/herbal supplements (folate, omega-3, passiflora, S-adenosyl methionine) for depression. Insufficient evidence was available on light therapy, inositol, valerian and selenium. Cochrane reviews of the

Table 2 Self-care interventions reported in surveys

\begin{tabular}{|c|c|c|c|}
\hline Intervention & $\begin{array}{l}\text { Patient/public use for depression or } \\
\text { anxiety or both? }\end{array}$ & $\begin{array}{l}\text { Number of surveys mentioning } \\
\text { intervention } \\
(\boldsymbol{N}=20)\end{array}$ & $\begin{array}{l}\text { Recommendations from } \\
\text { expert surveys }\end{array}$ \\
\hline Aromatherapy & Depression & 2 & - \\
\hline Bibliotherapy & Depression & 4 & Depression/anxiety \\
\hline Dietary changet & Depression & 6 & Depression/anxiety \\
\hline $\begin{array}{l}\text { Dietary supplements (other than vitamins/ } \\
\text { minerals or herbs) } \neq\end{array}$ & Depression & 5 & - \\
\hline Exercise & Depression & 11 & Depression/anxiety \\
\hline Herbal medicine§ & Depression/anxiety & 10 & Depression \\
\hline Homeopathy & Depression & 3 & - \\
\hline Internet self-help & Depression & 3 & Depression \\
\hline Massage & Depression/anxiety & 7 & - \\
\hline Meditation/mindfulness & Depression & 7 & Depression/anxiety \\
\hline Music & Depression & 3 & - \\
\hline Natural environments & Depression & 1 & Anxiety \\
\hline Pets/animals & Depression & 3 & Depression \\
\hline Prayer/spirituality & Depression & 4 & - \\
\hline Relaxation & Depression/anxiety & 10 & Depression/anxiety \\
\hline Self-help groups (not internet) & Depression & 5 & Depression \\
\hline Sunlight exposure & Depression & 1 & Depression \\
\hline Vitamins/minerals $\mathbf{q}$ & Depression/anxiety & 7 & - \\
\hline Yoga & Depression & 6 & Anxiety \\
\hline
\end{tabular}

tChanges included reducing caffeine, increasing caffeine, eating a high-carbohydrate diet, and reducing sugar, consuming cocoa or chocolate, improved diet ‡Non-vitamin, non-mineral, non-herbal dietary supplements and specific supplements including fish oil/omega-3, L-tryptophan or 5HTP, and SAMe $\S$ Herbal medicine in general and specific herbs including St. John's wort and chamomile

१ Vitamins in general, magnesium and vitamin-B complex 


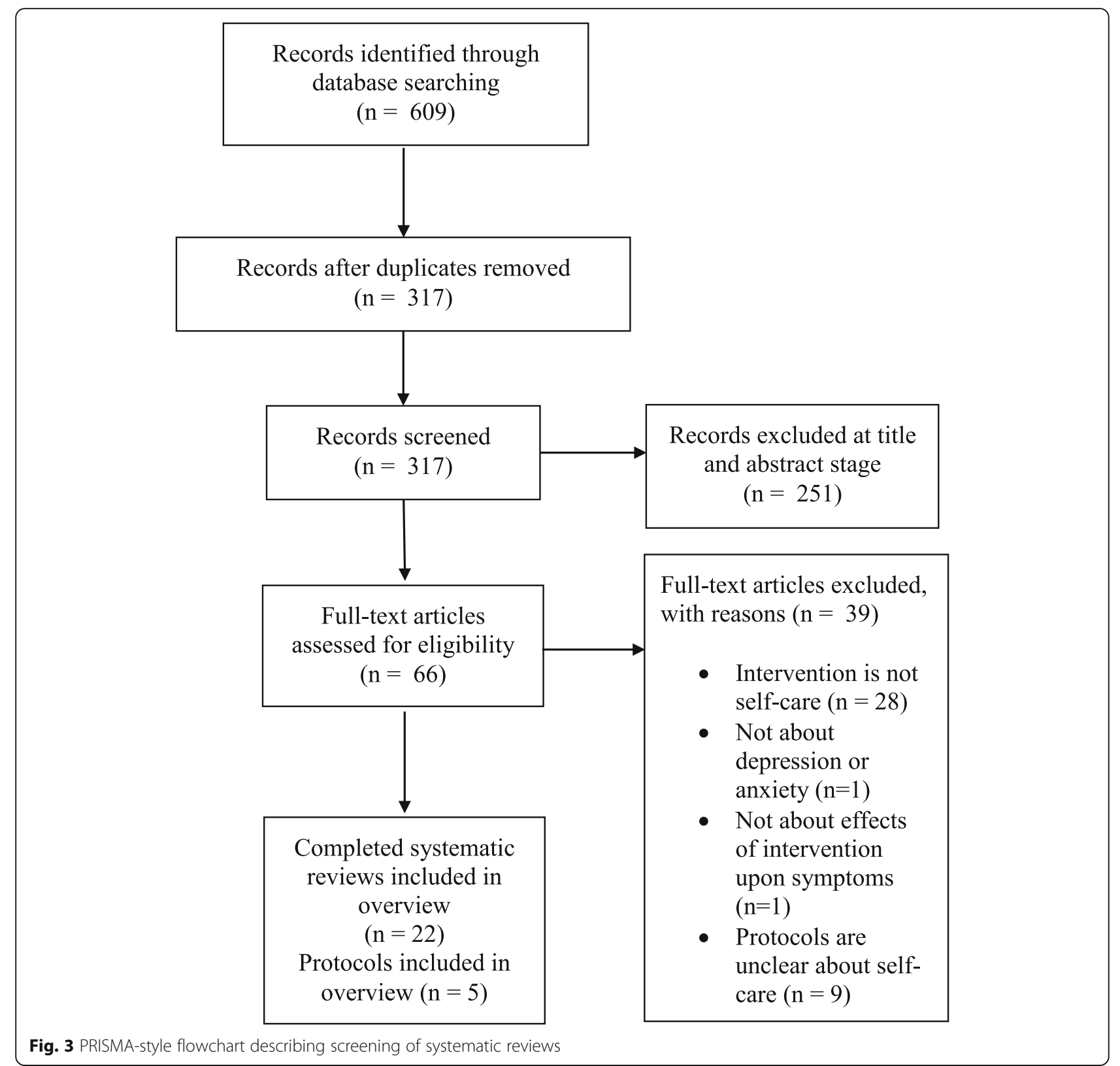

following have not been completed: aromatherapy, dietary change, homeopathy, massage, music, natural environments, pets/animals, prayer/spirituality, self-help groups (not internet) or yoga. See Table 3 for a description of review characteristics.

The readability of summaries varied considerably. The Flesch Reading Ease score for the plain language summaries of completed reviews ranged from 7.3 to 41.9 (median 29.75). Four summaries had Flesch Reading Ease scores lower than 20, and seven summaries had scores between 20 and 30, indicating that half of review plain language summaries were written on a readability level most suitable for college/university graduates.
Information in the PLS on risks/safety of interventions was limited (see Table 4). Ten reviews made no mention in the summaries of adverse events or potential harms (two of these reviews found no relevant studies) [50, 54, 56-60, 63, 64, 67]. Six review summaries stated explicitly that available information on harms was missing or limited from the included studies, without presenting any information on numbers or types of events that was available from the studies [52, 53, $61,65,66,73]$. Six review summaries discussed adverse events specifically $[47-49,51,55,62]$, and, of these, one review mentioned that the intervention was effective but potentially dangerous [47] while three summaries made a comparison between harms from the self-care intervention 
Table $\mathbf{3}$ Characteristics of included systematic reviews

Title (completed reviews)
Comparative effectiveness of continuation and maintenance treatments
for persistent depressive disorder in adults [64]
Light therapy for preventing seasonal affective disorder [66]
Melatonin and agomelatine for preventing seasonal affective disorder [67]
Psychosocial interventions for preventing and treating depression in
dialysis patients [65]
Interventions for treating anxiety after stroke [63]
S-adenosyl methionine (SAMe) for depression in adults [62]
Omega-3 fatty acids for depression in adults [61]
Media-delivered cognitive behavioural therapy and behavioural therapy
(self-help) for anxiety disorders in adults [59]
Dietary supplements for preventing postnatal depression [60]
Exercise for depression [58]
Psychosocial interventions for prevention of psychological disorders in law
enforcement officers [56]
Psychotherapeutic treatments for older depressed people [57]
Relaxation for depression [54]
St John's wort for major depression [55]
Passiflora for anxiety disorder [73]
Valerian for anxiety disorders [53]
Meditation therapy for anxiety disorders [52]
Light therapy for non-seasonal depression [51]
Inositol for depressive disorders [50]
Folate for depressive disorders [49]
Kava extract for treating anxiety [48]
Tryptophan and 5-Hydroxytryptophan for depression [47]
(6)

\section{Title (protocols)}

Antidepressants for major depression disorder in older people: a network meta-analysis [72]

Interventions (other than psychosocial, psychological and pharmacological) for treating postpartum depression [71]

The process and delivery of cognitive behavioural therapy (CBT) for depression in adults: a network meta-analysis [70]

Multimedia-delivered cognitive behavioural therapy versus face-to-face cognitive behavioural therapy for depression in adults [69]

Prevention of depression in chronically physically ill adults [68]

\author{
Year* Self-care intervention \\ 2019 Herbal (St. John's wort) \\ 2019 Light therapy \\ 2019 Dietary supplement (melatonin) \\ 2019 Acupressure, Exercise, Mind-body (meditation, \\ relaxation, spiritual practice), Social activity \\ 2017 Mind-body (relaxation) \\ 2016 Dietary supplement (SAMe) \\ 2015 Dietary supplement (Omega-3 fatty acids) \\ 2013 Psychological individual self-help \\ 2013 Dietary supplements (selenium yeast, EPA, DHA) \\ $2013+$ Exercise \\ 2008 Mind-body (relaxation), Exercise \\ 2008 Psychological individual self-help (bibliotherapy) \\ 2008 Mind-body (relaxation) \\ $2008^{\dagger}$ Herbal (St John's wort) \\ 2007 Herbal (Passiflora) \\ 2006 Herbal (Valerian) \\ 2006 Mind-body (meditation) \\ 2004 Light therapy \\ 2004 Dietary supplement (Inositol) \\ 2003 Dietary supplement (Folate) \\ 2003 Herbal (Kava) \\ 2002 Dietary supplement (Tryptophan and \\ 5-Hydroxytryptophan) \\ Year Self-care intervention \\ 2019 Dietary supplement (Tryptophan) \\ 2019 Mind-body (e.g. bright light therapy, physical exercise, \\ yoga, sleep deprivation); Dietary supplements \\ (e.g. omega-3 fatty acids); Herbal (e.g. St. John's Wort). \\ 2018 Multimedia CBT including self-help, Self-help CBT \\ without multimedia \\ 2018 Multimedia CBT including self-help \\ 2014 Psychological individual self-help (bibliotherapy)
}

*Year of most recent version of published review

tLast search for trials in 2013 and review has been split into two reviews for updating

and some other active intervention, in one case based on one trial [53] and in the others on several trials [55, 62].

\section{Comparison between strategies described in surveys and in Cochrane reviews}

A comparison between the surveys and Cochrane reviews reveals that several dietary supplements addressed by Cochrane reviews (omega-3, S-adenosyl methionine
(SAMe), tryptophan) appeared in only 1 survey; some (inositol and melatonin) were not specifically mentioned in any survey. Conversely, many types of self-care treatments mentioned in multiple surveys (aromatherapy, music, yoga) were not addressed in any Cochrane reviews. Some survey interventions were covered by Cochrane reviews but the review question was limited to specific populations (e.g., bibliotherapy for elderly 
Table 4 Comparison of interventions from surveys with relevant Cochrane reviews

\begin{tabular}{|c|c|c|c|}
\hline $\begin{array}{l}\text { Self-Care interventions } \\
\text { mentioned in multiple } \\
\text { patient/public or expert } \\
\text { surveys }\end{array}$ & $\begin{array}{l}\text { Focus of relevant Cochrane } \\
\text { review(s) }\end{array}$ & $\begin{array}{l}\text { Assessment of } \\
\text { effectiveness based on } \\
\text { Plain Language Summary } \\
(\mathrm{PLS}) \dagger\end{array}$ & Safety information in the PLS \\
\hline Aromatherapy & - & & \\
\hline \multirow[t]{2}{*}{ Bibliotherapy } & $\begin{array}{l}\text { media-delivered cognitive or } \\
\text { behavioural therapy for anxiety } \\
\text { disorders }\end{array}$ & + & - \\
\hline & $\begin{array}{l}\text { psychotherapeutic treatments for } \\
\text { older depressed people }\end{array}$ & No PLS & - \\
\hline Dietary change & - & & \\
\hline \multirow[t]{5}{*}{$\begin{array}{l}\text { Dietary supplements (other } \\
\text { than vitamins/minerals or } \\
\text { herbs) }\end{array}$} & $\begin{array}{l}\text { tryptophan and 5- } \\
\text { Hydroxytryptophan for depression }\end{array}$ & ++ & $\begin{array}{l}\text { Mentions side effects that have occurred; also that } \\
\text { tryptophan associated with development of a fatal } \\
\text { condition }\end{array}$ \\
\hline & $\begin{array}{l}\text { S-adenosyl methionine for } \\
\text { depression }\end{array}$ & + & $\begin{array}{l}\text { Mention of fewer side effects than with an } \\
\text { antidepressant }\end{array}$ \\
\hline & omega-3 fatty acids for depression & + & $\begin{array}{l}\text { Mentions that insufficient high quality evidence to } \\
\text { determine ... negative side effects }\end{array}$ \\
\hline & $\begin{array}{l}\text { dietary supplements (EPA or DHA) } \\
\text { for preventing postpartum } \\
\text { depression }\end{array}$ & $?$ & - \\
\hline & $\begin{array}{l}\text { melatonin for preventing seasonal } \\
\text { affective disorder }\end{array}$ & No evidence & - \\
\hline \multirow[t]{3}{*}{ Exercise } & exercise for depression & ++ & - \\
\hline & $\begin{array}{l}\text { psychosocial interventions to } \\
\text { prevent psychological disorders in } \\
\text { law enforcement personnel }\end{array}$ & $\begin{array}{l}\text { No mention of exercise in } \\
\text { PLS }\end{array}$ & - \\
\hline & $\begin{array}{l}\text { psychosocial interventions to } \\
\text { prevent and treat depression in } \\
\text { dialysis patients }\end{array}$ & ++ & Mentions adverse events very uncertain. \\
\hline \multirow[t]{5}{*}{ Herbal medicine } & kava extract for treating anxiety & ++ & $\begin{array}{l}\text { Mentions that few adverse events were reported in } \\
\text { the reviewed trials * }\end{array}$ \\
\hline & passiflora for anxiety disorders & + & $\begin{array}{l}\text { Mentions that not possible to draw any conclusions } \\
\text { on the safety }\end{array}$ \\
\hline & $\begin{array}{l}\text { St John's wort for major } \\
\text { depression }\end{array}$ & ++ & $\begin{array}{l}\text { Mention of fewer side effects than antidepressants; } \\
\text { that side effects are usually minor and uncommon } \\
\text { but effects of other drugs might be significantly } \\
\text { compromised. }\end{array}$ \\
\hline & valerian for anxiety disorders & $?$ & $\begin{array}{l}\text { Mentions that tolerated as well as an anxiolytic but } \\
\text { that further studies are needed for conclusions on } \\
\text { safety. }\end{array}$ \\
\hline & $\begin{array}{l}\text { continuation and maintenance } \\
\text { treatments for persistent } \\
\text { depressive disorder in adults }\end{array}$ & $\begin{array}{l}\text { No mention of St. John's } \\
\text { wort in PLS }\end{array}$ & - \\
\hline Homeopathy & - & & \\
\hline Internet-based self-help & $\begin{array}{l}\text { media-delivered cognitive or } \\
\text { behavioural therapy for anxiety } \\
\text { disorders }\end{array}$ & + & - \\
\hline Massage & - & & \\
\hline \multirow[t]{2}{*}{ Meditation/mindfulness } & $\begin{array}{l}\text { meditation therapy for anxiety } \\
\text { disorders }\end{array}$ & + & $\begin{array}{l}\text { Mentions that adverse effects have not been } \\
\text { reported }\end{array}$ \\
\hline & $\begin{array}{l}\text { psychosocial interventions to } \\
\text { prevent and treat depression in } \\
\text { dialysis patients }\end{array}$ & $?$ & Mentions adverse events very uncertain. \\
\hline Music & - & & \\
\hline Natural environments & - & & \\
\hline
\end{tabular}


Table 4 Comparison of interventions from surveys with relevant Cochrane reviews (Continued)

\begin{tabular}{|c|c|c|c|}
\hline $\begin{array}{l}\text { Self-Care interventions } \\
\text { mentioned in multiple } \\
\text { patient/public or expert } \\
\text { surveys }\end{array}$ & $\begin{array}{l}\text { Focus of relevant Cochrane } \\
\text { review(s) }\end{array}$ & $\begin{array}{l}\text { Assessment of } \\
\text { effectiveness based on } \\
\text { Plain Language Summary } \\
(\mathrm{PLS}) \dagger\end{array}$ & Safety information in the PLS \\
\hline Pets/animals & - & & \\
\hline Prayer/spirituality & $\begin{array}{l}\text { psychosocial interventions to } \\
\text { prevent and treat depression in } \\
\text { dialysis patients }\end{array}$ & $?$ & Mentions adverse events very uncertain. \\
\hline \multirow[t]{4}{*}{ Relaxation } & relaxation for depression & ++ & - \\
\hline & $\begin{array}{l}\text { interventions for treating anxiety } \\
\text { after stroke }\end{array}$ & $?$ & - \\
\hline & $\begin{array}{l}\text { psychosocial interventions to } \\
\text { prevent psychological disorders in } \\
\text { law enforcement personnel }\end{array}$ & $\begin{array}{l}\text { No mention of relaxation } \\
\text { in PLS }\end{array}$ & - \\
\hline & $\begin{array}{l}\text { psychosocial interventions to } \\
\text { prevent and treat depression in } \\
\text { dialysis patients }\end{array}$ & ++ & Mentions adverse events very uncertain. \\
\hline $\begin{array}{l}\text { Self-help groups (not } \\
\text { internet) }\end{array}$ & - & & \\
\hline \multirow[t]{2}{*}{ Sunlight exposure } & $\begin{array}{l}\text { light therapy** for preventing } \\
\text { seasonal affective disorder }\end{array}$ & $?$ & $\begin{array}{l}\text { Mentions that the included study provided no } \\
\text { information on side effects. }\end{array}$ \\
\hline & $\begin{array}{l}\text { light therapy** for non-seasonal } \\
\text { depression }\end{array}$ & $?$ & $\begin{array}{l}\text { Mentions a potential adverse effect that needs to be } \\
\text { considered. }\end{array}$ \\
\hline \multirow[t]{3}{*}{ Vitamins/minerals } & folate for depressive disorders & + & $\begin{array}{l}\text { Mentions that it was well-tolerated in the included } \\
\text { trials. }\end{array}$ \\
\hline & inositol for depressive disorders & $?$ & - \\
\hline & $\begin{array}{l}\text { dietary supplements (selenium) for } \\
\text { preventing postpartum depression }\end{array}$ & $?$ & - \\
\hline Yoga & - & & \\
\hline
\end{tabular}

tKey for statements in review PLS: -- no review; ++ effective; + promising;? unclear

* Comments on this review include report of possible liver toxicity

** Light therapy uses machines that simulate components of natural outdoor light

persons, relaxation to treat anxiety after stroke, exercise for dialysis patients) or covered only one indication when surveys indicated likely use for another indication (e.g., there is a Cochrane review of meditation for anxiety but surveys report that consumers might also use meditation for depression). Several reviews were excluded from this overview because they focused on interventions that could be used in self-care according to surveys, but the Cochrane review specifically focused on provision by a practitioner (e.g., music therapy for depression). Table 4 summarizes the interventions and corresponding Cochrane reviews.

\section{Discussion}

Self-care is increasingly emphasized by healthcare organizations as an approach to manage the ever-extending healthcare burden. It is also sought by many, particularly those with mental health conditions such as anxiety and depression. Informed decision-making does, however, require access to reliable information. Cochrane reviews provide coverage of self-care approaches and are a potentially useful source on these for health professionals and the general public. This study, using a novel and pragmatic approach, has highlighted where Cochrane reviews could be used to inform decision-making by patients or guidance by health professionals on frequently used self-care approaches. It has also highlighted the fact that there is currently some disparity between what is used in practice and the availability of reliable evidence. If the recommendations of organizations outside conventional healthcare are also taken into account, then the disparity may be greater [74]. Thus, there are clear evidence gaps to be filled by conducting and/or updating Cochrane reviews on those approaches used in practice. This will provide a more comprehensive resource for health care professionals aiming to guide patients through the possible options available. For resources such as Cochrane reviews to be optimal in informing self-care, there is, however, a need to ensure that the Plain Language Summary of each review is written using a consistent approach to content and organization and an appropriate reading level to allow maximum accessibility to patients and consumers. Achieving an optimal balance between transparency through detailed reporting 
of systematic reviews and an accessible, user-friendly summary is a considerable challenge. Nevertheless, if lay summaries suggest that intervention is safe and possibly effective, then it is important that the review should also contain accessible information on the intervention that allows the consumer to understand whether the review is applicable to his/her context. The results of this study suggest that providing the information in a way that allows comparison of more than one intervention would also be valuable. Currently, comparison between different therapies and approaches for a particular condition is neither easy nor quick.

As self-care may incorporate elements of self-diagnosis and self-monitoring, clearly written information on potential risks of treatments is also needed, with careful consideration on how this is worded and how might it be applied by members of the general public. For the practicing clinician, there is a dilemma to be addressed in that some of the more frequently used self-care approaches do not fit with current guidance but directly discouraging their use may also discourage their disclosure in consultations. Thus, being able to direct patients to reliable, accessible information on non-conventional as well as more conventional treatments or to use this a basis for discussions may be a positive step in ensuring effective patient-centered, evidence-informed care.

Limitations of this study include the fact that relying upon published surveys is an untested method for identifying the most commonly used or recommended interventions. The surveys were also heterogeneous in terms of sample, design and overall aims. Relying on the surveys we found and then using a practical rule of thumb (percentage of respondents reporting a therapy; at least two surveys mentioning a therapy) almost certainly resulted in omission of some strategies that are frequently used. However, our finding that there were no Cochrane reviews on many of the therapies that we did identify is not affected by this limitation. Additionally, identifying all relevant surveys proved challenging. It is possible that relevant surveys were not identified even though search strategies were specifically designed for this purpose and were based on preliminary scoping and testing of search terms. Reporting of the results of surveys was highly variable and some potentially relevant surveys had to be excluded as it was not possible to extract data on specific self-help therapies. Another limitation of this research is that we did not directly test the readability of the Cochrane plain language summaries but rather relied upon a commonly used rubric of readability, the Flesch Reading Ease test. Future exploration of this issue should directly test how comprehensible Cochrane plain language summaries are to readers and to what extent they answer their most pressing questions. Finally, the Cochrane reviews were selected as the 'gold standard' evidence on treatments but the quality of individual Cochrane reviews may vary. Furthermore, when Cochrane evidence on an intervention does not exist or is outdated, it is still possible that other reviews may have high-quality and up-to-date evidence on the topic. We focused on Cochrane not only because Cochrane reviews are generally considered to be methodologically rigorous and unbiased, but also because Cochrane aims to be a 'one-stop shop' for evidence and to translate this evidence into formats suitable for consumers as well as clinicians or researchers. Other well-conducted systematic reviews exist that are not part of the Cochrane Library and these do provide summaries of the evidence but these are generally less accessible to patients and consumers, and are not part of a globally available and updated database.

\section{Conclusion}

This study has revealed the interventions currently used in practice by the general public which were judged effective or promising based on Cochrane reviews. These include exercise, and relaxation for depression; bibliotherapy, internet based self-help and meditation for anxiety). Several herbs and nutritional supplements also fall into these categories. It has also highlighted the fact that there is currently some disparity between self-care approaches used in practice and the availability of reliable evidence. Greater clarity and consistency in presenting conclusions on safety is required, particularly for herbal and nutritional supplements. Being able to direct patients to reliable, accessible information on nonconventional as well as more conventional treatments is a positive step in ensuring effective patient-centered, evidence-informed care. The results of this study suggest that efforts should be made to address gaps, align evidence reviews with practice and ensure the consistency of evidence intended for the general public. The novel approach used in this study could be applied more widely to aid priority setting for systematic review topics, particularly as the emphasis increases on supporting evidence-based self-care.

\section{Appendix \\ Search strategies for identifying surveys of self-care for anxiety or depression \\ PubMed:}

((depression [Title] OR depressive [Title]) OR (anxiety [Title] or anxious [Title]) AND (usage [Title] OR survey [Title/Abstract]) AND (self-care [Title] OR selftreat:[Title] OR self-manage*[Title] OR self-prescri"[Title] OR complementary [Title] OR alternative [Title] OR overthe-counter [Title] OR OTC [Title]))

OR

((self-manage*[Title/Abstract] OR self-treat*[Title/Abstract] OR self-care [Title/Abstract] OR selfprescri*[Title/Abstract] OR over-the-counter [Title/ 
Abstract] OR OTC [Title/Abstract] OR complementary therapies [MeSH Terms]) AND ("Anxiety"[MeSH] OR "Anxiety Disorders"[MeSH] OR "Depression" [MeSH] OR "Depressive Disorder"[MeSH]) AND ("Surveys and Questionnaires" [MeSH] OR "Health Care Surveys"[$\mathrm{MeSH}]$ OR "Health Surveys"[MeSH]))

AMED (Ovid):

(depression OR depressive OR anxiety OR anxious) AND (usage OR survey) AND (self-care OR self-treat* OR self-manage* OR self-prescri* OR complementary OR alternative OR over-the-counter OR OTC) in title or abstract*

EMBASE (Ovid): As per AMED.

PsycInfo (EBSCO):

(depression OR depressive OR anxiety OR anxious) AND (usage (title) OR survey (title/abstract)) AND (selfcare OR self-treat* OR self-manage* OR self-prescri* OR complementary OR alternative OR over-the-counter OR OTC) in title or abstract.

* Term in italics added to most recent search to extend strategy.

\section{Abbreviations}

AMED: Allied and Complementary Medicine Database; CAM: Complementary and alternative medicine; CCMD: Cochrane Common Mental Disorders Review Group; CD: Cochrane Database; CBT: Cognitive behavioural therapy; DHA: Docosahexaenoic acid; EPA: Eicosapentaenoic acid; 5HTP: 5 Hydroxytryptophan; NHS: National Health Service; PLS: Plain Language Summary; PRISMA: Preferred Reporting Items for Systematic Reviews and Meta-Analyses; SAMe: S-adenosyl methionine; UK: United Kingdom; US: United States

\section{Acknowledgements}

Not applicable

\section{Authors' contributions}

KP and LSW conceived of the study, searched for relevant publications, extracted data from publications, and analyzed and interpreted the data. Both authors drafted and revised the manuscript and both authors approved the final manuscript.

\section{Funding}

Research reported in this publication was supported by the National Center for Complementary and Integrative Health of the National Institutes of Health under award number R24 AT001293. The content is solely the responsibility of the authors and does not necessarily represent the official views of the National Institutes of Health.

\section{Availability of data and materials}

The data that support the findings of this study are available from the survey and systematic review publications cited in the paper. The data extraction from these sources is available from the corresponding author upon reasonable request.

\section{Ethics approval and consent to participate}

Not applicable.

\section{Consent for publication}

Not applicable.

\section{Competing interests}

Dr. Pilkington is a Section Editor with BMC Complementary Medicine and Therapies. Dr. Wieland is a Systematic Review Editor with BMC

Complementary Medicine and Therapies and Coordinator of the Cochrane
Complementary Medicine Field. The authors declare that they have no further competing interests.

\section{Author details}

${ }^{1}$ School of Health and Care Professions, University of Portsmouth, James Watson West, 2 King Richard 1st Road, Portsmouth P01 2FR, UK. ${ }^{2}$ Center for Integrative Medicine, University of Maryland School of Medicine, 520 West Lombard Street, East Hall, Baltimore, MD 21201, USA.

Received: 19 December 2019 Accepted: 27 July 2020

Published online: 10 August 2020

\section{References}

1. World Health Organization South-East Asia Regional Office. Self care for health. 2014 https://apps.who.int/iris/handle/10665/205887 [Accessed 20 April 2020]

2. Grady PA, Gough LL. Self-management: a comprehensive approach to management of chronic conditions. Am J Public Health. 2014;104(8): e25-31.

3. Ryan A, Wilson S, Taylor A, Greenfield S. Factors associated with self-care activities among adults in the United Kingdom: a systematic review. BMC Public Health. 2009;9:96.

4. Lucock M, Gillard S, Adams K, Simons L, White R, Edwards C. Self-care in mental health services: a narrative review. Health Soc Care Community. 2011;19(6):602-16.

5. National Health Service. Online version of the NHS Long Term Plan. 2019. p. https://www.longtermplan.nhs.uk/online-version [Accessed 8 May 2019].

6. Sudo K, Kobayashi J, Noda S, Fukuda Y, Takahashi K. Japan's healthcare policy for the elderly through the concepts of self-help (Ji-jo), mutual aid (go-jo), social solidarity care (Kyo-jo), and governmental care (Ko-jo). Biosci Trends. 2018;12(1):7-11.

7. Yuefeng L, Keqin R, Xiaowei R. Use of and factors associated with selftreatment in China. BMC Public Health. 2012;12:995.

8. Mun S, Park JH, Baek SM, Lee M, Choi SM, Lee S. Self-care use patterns in the UK, US, Australia, and Japan: a multinational web-based survey. Integr Med Res. 2016:5(2):151-60.

9. Clement S, Schauman O, Graham T, Maggioni F, Evans-Lacko S, Bezborodovs $\mathrm{N}$, et al. What is the impact of mental health-related stigma on help-seeking? A systematic review of quantitative and qualitative studies. Psychol Med. 2015;45(1):11-27.

10. Haugen PT, McCrillis AM, Smid GE, Nijdam MJ. Mental health stigma and barriers to mental health care for first responders: a systematic review and meta-analysis. J Psychiatr Res. 2017;94:218-29.

11. Schnyder N, Panczak R, Groth N, Schultze-Lutter F. Association between mental health-related stigma and active help-seeking: systematic review and meta-analysis. Br J Psychiatry. 2017;210(4):261-8.

12. Mehta N, Clement S, Marcus E, Stona AC, Bezborodovs N, Evans-Lacko S, et al. Evidence for effective interventions to reduce mental health-related stigma and discrimination in the medium and long term: systematic review. Br J Psychiatry. 2015;207(5):377-84.

13. Rossom RC, Shortreed S, Coleman KJ, Beck A, Waitzfelder BE, Stewart C, et al. Antidepressant adherence across diverse populations and healthcare settings. Depress Anxiety. 2016;33(8):765-74.

14. Alonso J, Liu Z, Evans-Lacko S, Sadikova E, Sampson N, Chatterji S, et al. Treatment gap for anxiety disorders is global: results of the world mental health surveys in 21 countries. Depress Anxiety. 2018;35(3):195-208.

15. Thornicroft G, Chatterji S, Evans-Lacko S, Gruber M, Sampson N, AguilarGaxiola S, et al. Undertreatment of people with major depressive disorder in 21 countries. Br J Psychiatry. 2017;210(2):119-24

16. Morgan AJ, Jorm AF, Mackinnon AJ. Usage and reported helpfulness of selfhelp strategies by adults with sub-threshold depression. J Affect Disord. 2012;136(3):393-7.

17. Fullagar $S, O$ 'Brien W. Social recovery and the move beyond deficit models of depression: a feminist analysis of mid-life women's self-care practices. Soc Sci Med. 2014;117:116-24.

18. Chambers E, Cook S, Thake A, Foster A, Shaw S, Hutten R, et al. The selfmanagement of longer-term depression: learning from the patient, a qualitative study. BMC Psychiatry. 2015;15:172.

19. World Health Organization. Self-care can be an effective part of national health systems. 2019. p. https://www.who.int/reproductivehealth/self-carenational-health-systems/en/ [Accessed 20 April 2020]. 
20. World Health Organization. Fact Sheet: Self-care health interventions. 2020 p. https://www.who.int/news-room/fact-sheets/detail/self-care-healthinterventions [Accessed 20 April 2020].

21. Flesch R. A new readability yardstick. J Appl Psychology. 1948;32(3):221-33.

22. Flesch R. The art of plain talk. New York, NY: Harper \& Row; 1946.

23. Jorm AF, Griffiths KM, Christensen H, Parslow RA, Rogers B. Actions taken to cope with depression at different levels of severity: a community survey. Psychol Med. 2004;34(2):293-9.

24. Parker $G$, Crawford J. Judged effectiveness of differing antidepressant strategies by those with clinical depression. Aust N Z J Psychiatry. 2007;41:32-7.

25. Proudfoot J, Fogarty AS, McTigue I, Nathan S, Whittle EL, Christensen H, et al. Positive strategies men regularly use to prevent and manage depression: a national survey of Australian men. BMC Public Health. 2015;15:1135.

26. Parslow RA, Jorm AF. Use of prescription medications and complementary and alternative medicines to treat depressive and anxiety symptoms: results from a community sample. J Affect Disord. 2004;82(1):77-84.

27. Olesen SC, Butterworth P, Leach L. Prevalence of self-management versus formal service use for common mental disorders in Australia: findings from the 2007 National Survey of mental health and wellbeing. Aust N Z J Psychiatry. 2010;44(9):823-30

28. Holzinger A, Matschinger H, Angermeyer M. What to do about depression? Selfhelp recommendations of the public. Int J Soc Psychiatry. 2012;58(4):343-9.

29. Lowe B, Schulz U, Grafe K, Wilke S. Medical patients' attitudes toward emotional problems and their treatment. What do they really want? J Gen Intern Med. 2006;21(1):39-45.

30. Riedel-Heller SG, Matschinger H, Angermeyer MC. Mental disorders--who and what might help? Help-seeking and treatment preferences of the lay public. Soc Psychiatry Psychiatr Epidemiol. 2005;40(2):167-74.

31. Carta MG, Angermeyer MC, Matschinger H, Holzinger A, Pintus E, Pintus M, et al. Recommendations of the Sardinian public for the treatment of depression. Int J Soc Psychiatry. 2014;60(7):619-26.

32. Munizza C, Argentero P, Coppo A, Tibaldi G, Di Giannantonio M, Picci RL, et al. Public beliefs and attitudes towards depression in Italy: a national survey. PLoS One. 2013;8(5):e63806.

33. Shin EH, Ha J, Lim SW, Kwak SJ, Ryu SG, Ryu SH, et al. The use and perceived helpfulness of self-help interventions for depressive symptoms and sub-threshold depression: comparisons among the general population, patients with depression, and psychiatrists. Int J Methods Psychiatr Res. 2014;23(1):99-108.

34. van Grieken RA, van Tricht MJ, Koeter MWJ, van den Brink W, Schene AH. The use and helpfulness of self-management strategies for depression: the experiences of patients. PLoS One. 2018;13(10):e0206262.

35. Loureiro LM, Jorm AF, Mendes AC, Santos JC, Ferreira RO, Pedreiro AT. Mental health literacy about depression: a survey of portuguese youth. BMC Psychiatry. 2013;13:129.

36. Hsu MC, Moyle W, Creedy D, Venturato L, Ouyang WC, Tsay SL. Use of antidepressants and complementary and alternative medicine among outpatients with depression in Taiwan. Arch Psychiatr Nurs. 2009;23(1):75-85.

37. Tsai YF. Self-care management and risk factors for depressive symptoms among elderly nursing home residents in Taiwan. J Pain Symptom Manag. 2006;32(2):140-7.

38. Kessler RC, Soukup J, Davis RB, Foster DF, Wilkey SA, Van Rompay MI, et al. The use of complementary and alternative therapies to treat anxiety and depression in the United States. Am J Psychiatry. 2001;158(2):289-94.

39. Bazargan M, Ani CO, Hindman DW, Bazargan-Hejazi S, Baker RS, Bell D, et al. Correlates of complementary and alternative medicine utilization in depressed, underserved african american and Hispanic patients in primary care settings. J Altern Complement Med. 2008;14(5):537-44.

40. Bystritsky A, Hovav S, Sherbourne C, Stein MB, Rose RD, Campbell-Sills L, et al. Use of complementary and alternative medicine in a large sample of anxiety patients. Psychosomatics. 2012;53(3):266-72.

41. Musil CM, Givens SE, Jeanblanc AB, Zauszniewski JA, Warner CB, Toly VB. Grandmothers and self-Management of Depressive Symptoms. Arch Psychiatr Nurs. 2017;31(3):234-40.

42. Grzywacz JG, Suerken CK, Quandt SA, Bell RA, Lang W, Arcury TA. Older adults' use of complementary and alternative medicine for mental health: findings from the 2002 National Health Interview Survey. J Altern Complement Med. 2006;12(5):467-73.

43. Morgan AJ, Chittleborough P, Jorm AF. Self-help strategies for sub-threshold anxiety: a Delphi consensus study to find messages suitable for populationwide promotion. J Affect Disord. 2016;206:68-76.
44. Morgan AJ, Jorm AF. Self-help strategies that are helpful for subthreshold depression: a Delphi consensus study. J Affect Disord. 2009; 115(1-2):196-200.

45. Nordgreen T, Havik OE. Use of self-help materials for anxiety and depression in mental health services: a national survey of psychologists in Norway. Prof Psychol Res Pract. 2011;42(2):185-91.

46. van Grieken RA, van Tricht MJ, Koeter MWJ, van den Brink W, Schene AH. Correction: the use and helpfulness of self-management strategies for depression: the experiences of patients. PLoS One. 2018;13(12):e0209109.

47. Shaw K, Turner J, Del Mar C. Tryptophan and 5-hydroxytryptophan for depression. Cochrane Database of Systematic Reviews. 2002(1):doi: https:// doi.org/10.1002/14651858.cd003198.

48. Pittler MH, Ernst E. Kava extract for treating anxiety. Cochrane Database of Systematic Reviews. 2003(1):doi: https://doi.org/10.1002/14651858.cd003383.

49. Taylor MJ, Carney S, Geddes J, Goodwin G. Folate for depressive disorders. Cochrane Database of Systematic Reviews. 2003(2):doi: https://doi.org/10. 1002/14651858.cd003390.

50. Taylor MJ, Wilder H, Bhagwagar Z, Geddes J. Inositol for depressive disorders. Cochrane Database of Systematic Reviews. 2004(2):doi: https://doi org/10.1002/14651858.CD004049.pub2.

51. Tuunainen A, Kripke DF, Endo T. Light therapy for non-seasonal depression. Cochrane Database of Systematic Reviews. 2004(2):doi: https://doi.org/10. 1002/14651858.CD004050.pub2.

52. Krisanaprakornkit T, Krisanaprakornkit W, Piyavhatkul N, Laopaiboon M. Meditation therapy for anxiety disorders. Cochrane Database of Systematic Reviews. 2006(1):doi: https://doi.org/10.1002/14651858.CD004998.pub2.

53. Miyasaka LS, Atallah AN, Soares BG. Valerian for anxiety disorders. Cochrane Database of Systematic Reviews. 2006(4):doi: https://doi.org/10.1002/ 14651858.CD004515.pub2.

54. Jorm AF, Morgan AJ, Hetrick SE. Relaxation for depression. Cochrane Database of Systematic Reviews. 2008(4):doi: https://doi.org/10.1002/ 14651858.CD007142.pub2.

55. Linde K, Berner MM, Kriston L. St John's wort for major depression. Cochrane Database of Systematic Reviews. 2008(4):doi: https://doi.org/10. 1002/14651858.CD000448.pub3.

56. Penalba V, McGuire H, Leite JR. Psychosocial interventions for prevention of psychological disorders in law enforcement officers. Cochrane Database of Systematic Reviews. 2008(3):doi: https://doi.org/10.1002/14651858. CD005601.pub2.

57. Wilson KC, Mottram PG, Vassilas CA. Psychotherapeutic treatments for older depressed people. Cochrane Database of Systematic Reviews. 2008(1):doi: https://doi.org/10.1002/14651858.CD004853.pub2.

58. Cooney GM, Dwan K, Greig CA, Lawlor DA, Rimer J, Waugh FR, et al. Exercise for depression. Cochrane Database of Systematic Reviews. 2013(9): doi: https://doi.org/10.1002/14651858.CD004366.pub6.

59. Mayo-Wilson E, Montgomery P. Media-delivered cognitive behavioural therapy and behavioural therapy (self-help) for anxiety disorders in adults. Cochrane Database of Systematic Reviews. 2013(9):doi: https://doi.org/10. 1002/14651858.CD005330.pub4.

60. Miller BJ, Murray L, Beckmann MM, Kent T, Macfarlane B. Dietary supplements for preventing postnatal depression. Cochrane Database of Systematic Reviews. 2013(10):doi: https://doi.org/10.1002/14651858. CD009104.pub2.

61. Appleton KM, Sallis HM, Perry R, Ness AR, Churchill R. Omega-3 fatty acids for depression in adults. Cochrane Database of Systematic Reviews. 2015(11):doi: https://doi.org/10.1002/14651858.CD004692.pub4.

62. Galizia I, Oldani L, Macritchie K, Amari E, Dougall D, Jones TN, et al. Sadenosyl methionine (SAMe) for depression in adults. Cochrane Database of Systematic Reviews. 2016;10:doi: https://doi.org/10.1002/14651858. CD011286.pub2

63. Knapp P, Campbell Burton CA, Holmes J, Murray J, Gillespie D, Lightbody CE, et al. Interventions for treating anxiety after stroke. Cochrane Database of Systematic Reviews. 2017;5:doi: https://doi.org/10.1002/14651858.CD008860.pub3.

64. Machmutow K, Meister R, Jansen A, Kriston L, Watzke B, Härter M, et al. Comparative effectiveness of continuation and maintenance treatments for persistent depressive disorder in adults. Cochrane Database of Systematic Reviews. 2019(5):doi: https:/doi.org/10.1002/14651858.CD012855.pub2.

65. Natale P, Palmer S, Ruospo M, Saglimbene V, Rabindranath K, Strippoli G. Psychosocial interventions for preventing and treating depression in dialysis patients. Cochrane Database of Systematic Reviews. 2019(12):doi: https://doi. org/10.1002/14651858.CD004542.pub3. 
66. Nussbaumer-Streit B, Forneris C, Morgan L, Van NM, Gaynes B, Greenblatt A, et al. Light therapy for preventing seasonal affective disorder. Cochrane Database of Systematic Reviews. 2019(3):doi: https://doi.org/10.1002/ 14651858.CD011269.pub3.

67. Nussbaumer-Streit B, Greenblatt A, Kaminski-Hartenthaler A, Van NM, Forneris C, Morgan L, et al. Melatonin and agomelatine for preventing seasonal affective disorder. Cochrane Database of Systematic Reviews. 2019(6):doi: https://doi.org/10.1002/14651858.CD011271.pub3.

68. Kampling $\mathrm{H}$, Baumeister $\mathrm{H}$, Jäckel WH, Mittag O. Prevention of depression in chronically physically ill adults. Cochrane Database of Systematic Reviews [Internet]. 2014; (8). Available from: http://cochranelibrary-wiley.com/doi/10. 1002/14651858.CD011246/abstract.

69. Davies S, Caldwell D, Dawson S, Sampson S, Welton N, Wiles N, et al. Multimedia-delivered cognitive behavioural therapy versus face-to-face cognitive behavioural therapy for depression in adults. Cochrane Database of Systematic Reviews [Internet]. 2018; (11). Available from: http://dx.doi.org/ 10.1002/14651858.CD013184.

70. Davies S, Caldwell D, Lopez-Lopez J, Dawson S, Wiles N, Kessler D, et al. The process and delivery of cognitive behavioural therapy (CBT) for depression in adults: a network meta-analysis. Cochrane Database of Systematic Reviews [Internet]. 2018; (10). Available from: http://dx.doi.org/10.1002/ 14651858.CD013140.

71. Dennis C, Brown J, Brown H. Interventions (other than psychosocial, psychological and pharmacological) for treating postpartum depression. Cochrane Database of Systematic Reviews [Internet]. 2019; (11). Available from: http://dx.doi.org/10.1002/14651858.CD013460.

72. Robertson L, Bertolini F, Meader N, Davies S, Barbui C, Gilbody S, et al. Antidepressants for major depression disorder in older people: a network meta-analysis. Cochrane Database of Systematic Reviews [Internet]. 2019; (9). Available from: http://dx.doi.org/10.1002/14651858.CD013394.

73. Miyasaka LS, Atallah AN, Soares BG. Passiflora for anxiety disorder. Cochrane Database Syst Rev. 2007;(1). https://doi.org/10.1002/14651858.CD004518.pub2.

74. Long L, Huntley A, Ernst E. Which complementary and alternative therapies benefit which conditions? A survey of the opinions of 223 professional organizations. Complementary therapies in medicine. 2001;9(3):178-85.

\section{Publisher's Note}

Springer Nature remains neutral with regard to jurisdictional claims in published maps and institutional affiliations.

Ready to submit your research? Choose BMC and benefit from:

- fast, convenient online submission

- thorough peer review by experienced researchers in your field

- rapid publication on acceptance

- support for research data, including large and complex data types

- gold Open Access which fosters wider collaboration and increased citations

- maximum visibility for your research: over $100 \mathrm{M}$ website views per year

At $\mathrm{BMC}$, research is always in progress.

Learn more biomedcentral.com/submissions 